\title{
In Adolescence, Female Rats Are More Sensitive to the Anxiolytic Effect of Nicotine Than Are Male Rats
}

\author{
Survjit Cheeta, B.Sc., Ph.D., Elaine E. Irvine, B.Sc, M.Sc., Sonia Tucci, M.Sc., M.D., \\ Jasdeep Sandhu, and Sandra E. File, B.Sc., Ph.D., D.Sc.
}

\begin{abstract}
Anxiety may play an important role in the onset of smoking, particularly in young girls. This study examined whether there were sex differences in the effects of nicotine on anxiety in adolescent rats and whether social isolation modified these effects. Male and female adolescent rats were housed in groups of the same sex or in social isolation for seven days prior to testing in the social interaction test of anxiety. Nicotine increased social interaction in both males and females, and because there was no concomitant change in locomotor activity, this indicated anxiolytic effects.

However, there was a 5-fold sex difference in the lowest dose required to enhance social interaction, with an anxiolytic effect in females at $0.05 \mathrm{mg} / \mathrm{kg}$, but in males only at $0.25 \mathrm{mg} /$
\end{abstract}

$\mathrm{kg}$. Furthermore, in males the anxiolytic effect was seen only in socially isolated animals, whereas in the females it was present in both housing conditions. The depressant effect of nicotine on locomotor activity also depended on both the sex of the animal and on their housing conditions, with greater effects in singly housed animals and in males. This sex difference in sensitivity to nicotine's anxiolytic effects suggests there may be sex differences in the factors initiating and maintaining teenage smoking.

[Neuropsychopharmacology 25:601-607, 2001] (C) 2001 American College of Neuropsychopharmacology. Published by Elsevier Science Inc.
KEY WORDS: Nicotine; Sex differences; Adolescence; Anxiety; Social isolation

Since 1972 the prevalence of smoking in Britain has been measured regularly as part of the General Household Survey. In the first year of the survey, $52 \%$ of men and $41 \%$ of women in Britain were regular cigarette

From the Psychopharmacology Research Unit, Centre for Neuroscience, GKT School of Biomedical Sciences, King's College London, Hodgkin Building, Guy's Campus, London SE1 1UL, UK.

Address correspondence to: Dr. S. E. File, King's College, Centre for Neuroscience, Psychopharmacology Research Unit, Hodgkin Building, Guy's Campus, London SE1 1UL, UK.

E-Mail: sandra.file@kcl.ac.uk

Received December 19, 2000; revised March 7, 2001; accepted March 13, 2001.

Online publication: 3/29/01 at www.acnp.org/citations/Npp 03290197. smokers. The prevalence of smoking then declined progressively in both sexes resulting in a prevalence of $28 \%$ for men and 26\% for women (Royal College Physicians 2000), a prevalence and sex pattern that is consistent with findings from other countries (Mortality Morbidity Weekly Report 2000a,b; Health Canada 1999). However, in the younger age groups smoking prevalence has in fact been stable, or increasing, in recent years, particularly in females. Thus, for some time, females have accounted for the majority of young smokers entering the smoking population (Royal College of Physicians 2000; Seguire and Chalmers 2000). In a longitudinal cohort study in New Zealand, Stanton et al. (1996) found a major increase in the incidence of smoking between ages 15 and 18, with significantly more girls $(35.4 \%)$ than boys (27.5\%) smoking daily. This early sex difference in smoking is important, since studies have shown that the early initiation of smoking results in 
more daily consumption of cigarettes, and decreases the probability of quitting smoking (Chen and Millar 1998; Nelson et al. 1995; Pierce and Gilpin 1996). This is particularly alarming since women seem to be at even greater risk than men for smoking related diseases including lung cancer (Zang and Wynder 1996) and myocardial infarction (Prescott et al. 1998). Pregnancy disorders and reproductive diseases related to the use of tobacco pose an additional cause for concern (Seguire and Chalmers 2000).

It has been assumed that the major factor leading to the onset of regular smoking is the rewarding effect of nicotine, but there may be important sex differences, with males showing greater sensitivity to these effects than females (Perkins et al. 1999). Smokers as a reason for their smoking frequently cite a calming or anxietyreducing effect and this is particularly prevalent among teenage girls (Crisp et al. 1999). This sex difference may explain why the anxiolytic drug, clonidine, was effective in promoting smoking cessation in women, but not men (Glassman et al. 1998). During early adolescence, females may be unusually vulnerable to stress, perceiving events to be more stressful than at other ages and than as perceived by males (Spear 2000), and they are more likely than males to smoke to relieve negative withdrawal symptoms (Stanton 1995). Sex differences in the response to nicotine after stress have also been found in non-smoking students. Under conditions of stress, while nicotine enhanced anxiety and aggression in males, it had calming effects in females (File et al. 2001).

Sex differences in response to nicotine have been found in animal studies. In a self-administration paradigm, Donny et al. (2000) found the motivation to obtain nicotine was higher in female than in male rats and, in a drug discrimination paradigm, acute nicotine produced greater anxiety-like behavior in male than in female rats (Jung et al. 2000). Bimodal effects of nicotine in animal tests of anxiety are now well recognized. Although nicotine has been reported to have anxiolytic effects in several animal tests (Brioni et al. 1993; Cao et al. 1993; Costall et al. 1989; Vale and Green 1986), anxiogenic effects have also been documented (Morrison 1969; Ouagazzal et al. 1999; Jung et al. 2000). In the social interaction test of anxiety, the effects of nicotine in adult rats were shown to be dose-dependent, with low doses having anxiolytic effects and high doses having anxiogenic effect (File et al. 1998). In adult male rats, the stress of social isolation increased sensitivity to both nicotine's anxiolytic and anxiogenic effects (Cheeta et al. 2001a).

Whereas numerous studies have explored the consequences of fetal or adult nicotine exposure, basic research is notable for the lack of attention to the effects of nicotine exposure during adolescence, the developmental period during which regular cigarette use typically begins. The periadolescent period in rats occurs around days $29-42$, and is a period of intense socialization and rapid neural development (Spear and Brake 1983). Initial investigations with a rat model of adolescent nicotine exposure have demonstrated that this is a vulnerable developmental period for nicotine-induced brain cell damage (Trauth et al. 2000a). Sex differences were also found at this age in withdrawal responses to nicotine with females, but not males, showing decreased locomotor activity and rearing (Trauth et al. 2000b). The purpose of the present study was to determine whether there were sex differences in the response to nicotine of adolescent rats in the social interaction test of anxiety, and whether these were modified by social isolation.

This social interaction test of anxiety has been validated extensively in adult male rats (File and Hyde 1978; File 1980) and is also suitable for use with adolescent males and females (File and Tucker 1984a; File 1987). In this test the dependent variable is the time spent in social interaction by pairs of rats. Specific increases in social interaction are indicative of an anxiolytic effect and decreases indicate an anxiogenic response. The light level and familiarity of the test arena can be varied in order to modify the level of anxiety generated by the test. A moderate level of anxiety is generated by testing in a brightly lit arena, with which the rats have been familiarized. This is the test condition selected for this experiment, since it has proved sensitive to both the anxiolytic and the anxiogenic effects of nicotine (File et al. 1998; Irvine et al. 1999).

\section{MATERIALS AND METHODS}

\section{Animals}

A total of 300 Lister hooded rats (150 males and 150 females; Harlan Olac, Bicester, UK) aged 28 days were housed either in isolation or in the same sex social groups of five for seven days prior to the start of the behavioral testing. The rats were tested between 35-39 days of age. Isolation housed rats were housed singly in a cage $45 \mathrm{~cm} \times 28 \mathrm{~cm} \times 20 \mathrm{~cm}$ high. The group-housed cages were $56 \mathrm{~cm} \times 38 \mathrm{~cm} \times 20 \mathrm{~cm}$ high. All cages were in racks that allowed rats to see, hear and smell other rats. Food and water were freely available to all the animals. The room in which the animals were housed was lit with dim light and maintained at $22^{\circ} \mathrm{C}$. Lights were on from 7 A.M. to 7 P.M. The experimental procedures carried out in this study were in compliance with the UK Animals (Scientific Procedures) Act 1986 (Home Office Project Licence Number 70/4041)

\section{Apparatus}

The social interaction test arena was a wooden box $60 \mathrm{~cm} \times 60 \mathrm{~cm}$, with $35 \mathrm{~cm}$ walls, and was lit by high 
light (300 lux). A camera was mounted vertically above the arena and the rats were observed on a monitor in an adjacent room. The time spent in social interaction (sniffing, following, grooming the partner, boxing and wrestling) provided the measure of anxiety and was scored by an observer who was blind to the drug treatment. The interruption of infrared beams from photocells mounted in the walls $3.5 \mathrm{~cm}$ from the floor provided an automated measure for locomotor activity (for details see File and Hyde 1978; File 1980, 1997).

\section{Drug}

(-)-Nicotine hydrogen tartrate (Sigma, Poole, UK) was dissolved in distilled water, and the doses of nicotine were calculated as the base. All drug injections were given subcutaneously (s.c.) in a volume of $1 \mathrm{ml} / \mathrm{kg}$ body weight. Control animals received equal volume injections of distilled water. The animals were tested 30 min after injection.

\section{Procedure}

Each rat was placed individually, undrugged, in the test arena for a 5-min familiarization trial on the day prior to the social interaction test. Rats were allocated to test partners on the basis of weight, so they did not differ by more than $10 \mathrm{~g}$. For the group-housed rats, the test partner was always taken from a different cage and both were always of the same sex. After testing the rats were returned to their home cages, so that grouphoused animals always remained in a group of at least four. Seventy-four pairs of singly-housed ( 37 males and 37 females) and 76 pairs of group-housed rats ( 38 males and 38 females) were randomly allocated among the five drug groups: vehicle, or (-)-nicotine $0.05,0.1,0.25$ or $0.5 \mathrm{mg} / \mathrm{kg}$. Both members of a pair received the same dose of nicotine on the test day and $30 \mathrm{~min}$ after injection they were placed in the center of the test arena. Their behavior was scored for $4.5 \mathrm{~min}$ from a monitor in the adjacent room, by an observer with no knowledge of the drug treatment. The rats were tested between 9 A.M. and 1 P.M. The social interaction scores that were analyzed were the total times spent interacting by both members of the pair of rats (i.e. a single score for each pair of rats). This is because the behavior of one rat cannot be considered to be independent of its partner's behavior. At the end of the trial any feces were removed and the arena wiped with a damp cloth.

\section{Statistics}

The data for the dose-response to nicotine were analyzed by a three factor analysis of variance (Factor 1, housing; Factor 2, sex; Factor 3, drug treatment). After the analysis of variance, comparisons between indi- vidual groups were made with Fisher's post-hoc test and it is the significances of these that are shown in figure 1 .

\section{RESULTS}

The adolescent rats housed in isolation spent significantly more time in social interaction than did those that were housed in social groups $[\mathrm{F}(1,130)=540.82, p<.00001$; upper panel in Figure 1]. The effects of nicotine depend on the combination of sex and housing conditions [housing $\mathrm{X} \operatorname{sex} \mathrm{X}$ drug interaction, $\mathrm{F}(4,130)=28.98, p<.00001]$. Thus, in the socially isolated rats, the lowest doses of nicotine $(0.05$ and $0.1 \mathrm{mg} / \mathrm{kg})$ significantly increased social interaction in females, while a similar anxiolytic
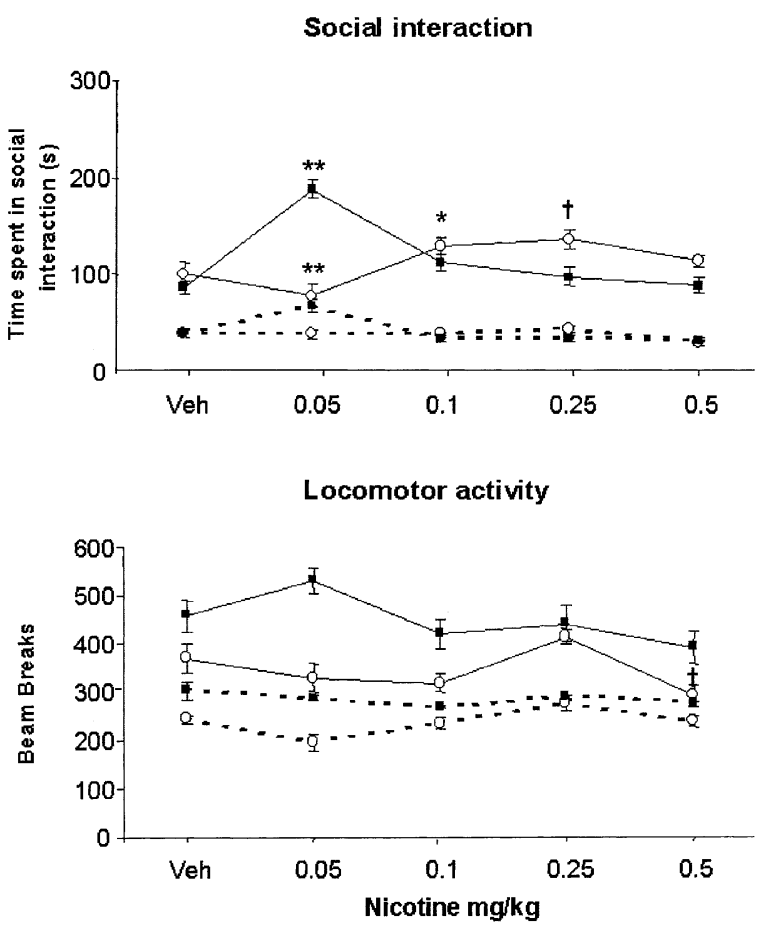

Figure 1. Upper panel: Mean ( \pm SEM) time (seconds) spent in social interaction by male (open circles) and female (solid squares) adolescent rats housed in social isolation (solid lines) or in social groups (hatched lines) for seven days. Rats were tested $30 \mathrm{~min}$ after injection with vehicle or (-)-nicotine $\left(0.05,0.1,0.25\right.$ or $0.5 \mathrm{mg} / \mathrm{kg}$ s.c.). ${ }^{\dagger}$ represents male differences and * represents females, one symbol $=p<$ .05 , two symbols $=p<.01$ compared with appropriate vehicle control group. Lower panel: Mean ( \pm SEM) locomotor activity (beam breaks) of male (open circles) and female (solid squares) rats housed in social isolation (solid lines) or in social groups (hatched lines) for seven days and then tested $30 \mathrm{~min}$ after injections of vehicle or (-)-nicotine $(0.05$, $0.1,0.25$ or $0.5 \mathrm{mg} / \mathrm{kg}$ s.c.) ${ }^{\dagger} p<.05$ socially isolated males compared with its own vehicle control. 
effect was evident in males only at a higher dose $(0.25$ $\mathrm{mg} / \mathrm{kg}$ ). In comparison, in the adolescent rats housed in social groups, a significant increase in social interaction was seen only in females and only at the lowest nicotine dose $(0.05 \mathrm{mg} / \mathrm{kg})$, and no effect was seen in males.

As can be seen from Figure 1 (lower panel), adolescent rats housed in isolation had higher motor activity than the adolescent rats housed in social groups $[\mathrm{F}(1,130)=168.58, p<.00001]$, and female adolescent rats had higher motor activity than male adolescents $[F(1,130)=53.44, p<.00001]$. The effect of nicotine was dependent on housing [drug $\times$ housing interaction, $\mathrm{F}(4,130)=2.6, p<.05]$, and also on sex [drug $\times$ sex interaction, $\mathrm{F}(4,130)=3.7, p<.01]$, and it can be seen from the lower panel of Figure 1 that the greatest sensitivity to the sedative effects of nicotine was shown by the socially isolated adolescent male rats.

\section{DISCUSSION}

The increased social interaction in the socially isolated adolescent rats confirmed earlier findings on the effects of social isolation during adulthood (File and Pope 1974; Niesink and Van Ree 1982; Varlinskaya et al. 1999; Cheeta et al. 2001a). This increased interaction is the main reason for routinely using singly-housed rats in this test. However, the social interaction test has been used in group-housed rats (Jones et al. 1988; Dunn et al. 1991; Costall et al. 1993) and it is possible to detect anxiolytic effects of benzodiazepines in both housing conditions (File and Hyde 1978; File 1980; Dunn et al. 1991; Gardner and Guy 1984). The anxiolytic effect of nicotine can also be detected in group-housed and socially isolated adult male rats, but it was manifested at a much wider dose-range in the socially isolated adult male rats (Cheeta et al. 2001a). The results of the present experiment show that the effect of the housing conditions was even more marked in adolescent rats. In the grouphoused rats, no anxiolytic effects of nicotine were detected in the adolescent males, and the effect was manifest at only one dose in the adolescent females. This is perhaps surprising, since in general it is easier to detect increases in behavior when baseline scores are low (e.g. Crawley and Davis 1982). Rate-dependent effects of nicotine have been detected in a wide range of behaviors, including its reinforcing effects (Perkins 1999). Thus, it would seem to be the stress, or some other effect, of social isolation, rather than the baseline scores per se, that was enhancing the anxiolytic effects of nicotine in this test. The socially isolated rats had higher locomotor activity scores than did the group-housed rats and a ratedependent effect of nicotine could explain the locomotor depressant effect that was detected only in the socially isolated animals. However, it cannot explain why this was detected only in the socially isolated males.
In both male and female adolescent rats, nicotine increased social interaction, without increasing locomotor activity, thus indicating specific anxiolytic effects. However, there was a 5-fold sex difference in the lowest dose required to significantly enhance social interaction. While in male adolescent rats an anxiolytic effect was seen with a dose of $0.25 \mathrm{mg} / \mathrm{kg}$ nicotine, in the females it was evident with the lower dose of $0.05 \mathrm{mg} / \mathrm{kg}$. The enhanced sensitivity in the adolescent female rats to the anxiolytic effects of nicotine is similar to the sex difference previously found in students (File et al. 2001). However, the significant drug sex interaction indicated that, overall, male adolescent rats were more sensitive than the females to the locomotor depressant effect of nicotine. A similar sex difference has also been found in adult mice (Hatchell and Collins 1980), but was not found in adult rats (Kanyt et al. 1999). Male adult rats trained to a pentylenetetrazol cue showed greater response than females to the anxiogenic and sedative discriminative effects of a high dose of nicotine (Jung et al. 2000). Male adult rats were more sensitive than females to the discriminative effects of a nicotine cue (Schecter and Rosecrans 1971), which is thought to be linked to its reinforcing effect and the same sex difference was found for men and women (Perkins 1999). It is therefore possible that males are more sensitive to the effects of high doses of nicotine and females are more sensitive to the effects of low doses. Alternatively, the data indicate that, whereas males are more sensitive to the reinforcing effects of nicotine, females are more sensitive to its anxiolytic effects.

In the present study the anxiolytic effect of nicotine was not found to be dose-dependent, but rather present at single or multiple doses in both the male and female adolescent rats. The lack of dose-dependency of nicotine's effects in the social interaction test of anxiety has also previously been reported in adult male rats (File et al. 1998; Cheeta et al. 2001a). Furthermore, the anxiolytic effects of nicotine in the fear-potentiated startle and the elevated plus maze are not dose-dependent (Vale and Green 1996; Brioni et al. 1993). However, dose-dependent anxiolytic effects of nicotine have been reported in mice in the light-dark crossing test (Costall et al. 1989), and the mirrored chamber (Cao et al. 1993). These findings raise the possibility of species differences in the effects of nicotine as well as differences that depend on the particular animal test of anxiety. Since different animal tests are thought to measure different underlying states of anxiety (File 1992), the effects of nicotine in the present study cannot necessarily be generalized to other animal tests of anxiety. The results of the present study are most likely to be pertinent to generalized anxiety disorder, since this is the disorder most closely modelled by the social interaction test. While the period of adolescence is known to overlap with puberty, unlike puberty it is not characterized by distinct 
neuroendocrinological changes (Spear 2000). It is therefore unlikely that the sex differences in response to nicotine in adolescent rats are due to hormonal differences, and more likely that they result from the neural alterations that occur in the brain during adolescence.

The fact that the sex differences in response to nicotine vary according to the effect under investigation is not surprising, since different neurotransmitters and different brain regions mediate the different effects of nicotine. Thus, the anxiolytic effect of low doses of nicotine is mediated by nicotine stimulating the release of $5-\mathrm{HT}$, which then acts on somatodendritic $5-\mathrm{HT}_{1 \mathrm{~A}}$ autoreceptors in the dorsal raphe nucleus (Cheeta et al. 2001b). Interestingly, there are sex differences in response to $5-\mathrm{HT}_{1 \mathrm{~A}}$ receptor agonists, with female rats showing greater sensitivity to their anxiolytic effects (Blanchard et al. 1992). The anxiogenic effects of nicotine are mediated by stimulation of postsynaptic $5-\mathrm{HT}_{1 \mathrm{~A}}$ receptors in limbic regions, such as the dorsal hippocampus and lateral septum (Kenny et al. 2000; Cheeta et al. 2000). The rewarding effects of nicotine are thought to be mediated by enhanced dopamine release in the nucleus accumbens (DiChiara and Imperato 1988). It would therefore be of great interest to determine whether sex differences can be detected to the effects of nicotine directly administered into these brain areas.

This study also raises the possibility that adolescent males are less sensitive to the effects of nicotine than are adult males. Although a direct comparison was not made in this experiment, in a study immediately preceding this one anxiolytic effects of nicotine were evident in adult male rats in the dose range of 0.05-0.1 $\mathrm{mg} / \mathrm{kg}$ (File et al. 1998; Cheeta et al. 2001a), whereas in the adolescent males an anxiolytic effect of nicotine was not seen until a dose of $0.25 \mathrm{mg} / \mathrm{kg}$. A similar lack of sensitivity in the adolescents may also occur with respect to the anxiogenic effect of nicotine, which was observed in adult rats at $0.5 \mathrm{mg} / \mathrm{kg}$ (File et al. 1998; Cheeta et al. 2001a), but was not seen in the present study on adolescents. Finally, the adolescent males appeared less sensitive to the locomotor depressant effects of nicotine, which reached significance at $0.25 \mathrm{mg} / \mathrm{kg}$ in adult males (Cheeta et al. 2001a) but only at $0.5 \mathrm{mg} / \mathrm{kg}$ in the adolescent males. A direct age-comparison study is needed to confirm these possible age differences. Adolescent rats have also been shown to be less sensitive to the anxiolytic effects of diazepam in the social interaction test (Primus and Kellogg 1990) and, in general, adolescence is a period of reduced sensitivity to psychostimulant drugs (Spear 2000). We are unable to make similar comparisons between female adolescent and adult animals, because of concerns that the social interaction test may not be valid in adult females because they do not show an increase in social interaction with familiarization (Johnston and File 1991). This is likely to be because social interaction serves very differ- ent functions in the adult male and female. However, both adolescent male and female rats do respond with increases in social interaction to familiarity with the test arena and thus the test seems valid for both sexes at this age (File and Tucker, 1984b). In the present study following nicotine administration, the adolescent females showed a behavioral profile which was very similar to one previously reported in the adult male rats (File et al. 1998; Cheeta et al. 2001a). In group-housed rats, the anxiolytic effects of nicotine were only evident at single doses in both adult males and adolescent female rats. Furthermore, in singly-housed rats the anxiolytic effects of nicotine were present over a much wide dose-range in both these groups. However, anxiogenic effects of nicotine are reported in singly-housed adult male rats (File et al. 1998; Cheeta et al. 2001a), and this finding contrasts with the present observations in the adolescent females. Nevertheless, these findings raise the interesting possibility that the sex differences observed in the present study may result from differential rates of development between the sexes, with female adolescent rats behaving in a similar way to adult male rats.

In conclusion, these findings suggest that there are important differences in the effects of nicotine on adolescent male and female rats. This reinforces the earlier suggestion (Pomerleau et al. 1991) that nicotine may have different effect on women than men. This is particularly pertinent when considering the effects of pharmacological agents to treat smoking. Nicotine replacement therapies are less successful in women than in men (Killen et al. 1990; Fortmann and Killen 1994; Kabat and Wynder 1987) and it would be interesting to determine whether treatments that have anxiolytic or antidepressant effects are more effective in women than in men. The results with the clonidine trial (Glassman et al. 1988) suggest that they might be, although there appears to be no sex difference in the response to bupropion (Hurt et al. 1997; Jorenby et al. 1999). There is high comorbidity of anxiety, depression and substance abuse in both men and women. However, whereas in men substance abuse disorders tend to precede mental disorders, in women the mental disorders are primary (Kessler and Wittchen 1999). This has considerable implications both for the initiation of smoking and for its cessation.

\section{ACKNOWLEDGMENTS}

This study was supported by grants from the Wellcome Trust and CONICIT-ULA, Venezuela.

\section{REFERENCES}

Blanchard DC, Shepherd JK, Rodgers RJ, Blanchard RJ (1992): Evidence for differential effects of 8-OH-DPAT 
on male and female rats in anxiety/defense test battery. Psychopharmacology 106:531-539

Brioni JD, O’Neill AB, Kim DJ, Decker MW (1993): Nicotinic receptor agonists exhibit anxiolytic-like effects on the elevated plus-maze test. Eur J Pharmacol 238:1-8

Cao W, Burkholder T, Wilkins L, Collins AC (1993): A genetic comparison of the behavioral actions of ethanol and nicotine in the mirrored chamber. Pharmacol Biochem Behav 45:803-809

Cheeta S, Kenny PJ, File SE (2000): The role of 5-HT $\mathrm{HA}_{1 \mathrm{~A}}$ receptors in mediating the anxiogenic effects of nicotine following lateral septal administration. Eur J Neurosci 12:3797-3802

Cheeta S, Irvine E, File SE (2001a): Social isolation modifies nicotine's effects in animal tests of anxiety. Br J Pharmacol (in press)

Cheeta S, Irvine E, Kenny P, File SE (2001b): The dorsal raphé nucleus is a crucial structure mediating nicotine anxiolytic effects and the development of tolerance and withdrawal responses. Psychopharmacology (in press)

Chen J, Millar WJ (1998): Age of smoking initiation: Implications for quitting. Health Rep 9:39-46

Costall B, Kelly ME, Naylor RJ, Onaivi, ES, Wong EH, Smith WL, Whiting, RL, Eglin RM (1989): The actions of nicotine and cocaine in a mouse model of anxiety. Pharmacol Biochem Behav 33:197-203

Costall B, Domeney AM, Kelly ME, Tomkins DM, Naylor RJ, Wong EHF, Smith WL, Whiting RL, Eglen RM (1993): The effect of the 5-HT3 receptor antagonist, RS-42358197, in animal models of anxiety. Eur J Pharmacol 234:91-99

Crawley JN, Davis LG (1982): Baseline exploratory activity predicts anxiolytic responsiveness to diazepam in five mouse strains. Brain Res Bull 8:609-612

Crisp A, Sedgwick P, Halek C, Joughin N, Humphrey H. (1999): Why may teenage girls persist in smoking? J Adolesc 22:657-672

DiChiara G, Imperato A (1988): Drugs abused by humans preferentially increase synaptic dopamine concentrations in the mesolimbic system of freely moving rats. Proc Natl Acad Sci USA 85:5274-5278

Donny EC, Caggiula AR, Rowell PP, Gharib MA, Maldovan V, Booth S, Mielke MM, Hoffman A, McCallum S (2000): Nicotine self-administration in rats: estrous cycle effects, sex differences and nicotinic receptor binding. Psychopharmacology 151:392-405

Dunn RW, Carleaon WA, Corbett R (1991): Preclinical anxiolytic versus antipsychotic profiles of the $5-\mathrm{HT}_{3}$ antagonists ondansetron, zacopride, $3 \alpha$-tropanyl- $1 \mathrm{H}$-indole3 -carboxylic acid ester, and $1 \alpha \mathrm{H}, 3 \alpha, 5 \alpha \mathrm{H}$-tropan-3-yl3,5-dichlorobenzoate. Drug Develop Res 23:289-300

File SE (1980): The use of social interaction as a method for detecting anxiolytic activity of chlordiazepoxide-like drugs. J Neurosci Meth 2:219-238

File SE (1987): Diazepam and caffeine administration during the first week of life: changes in neonatal and adolescent behavior. Neurobehav Teratol Toxicol 9:9-16

File, SE (1992) Behavioural detection of anxiolytic action. In Elliot JM et al. (eds), Experimental approaches to anxiety and depression. London, John Wiley, pp 25-44
File SE (1997): Animal measures of anxiety. In Crawley J, Gerfen C, McKay R, Rogawski MA, Sibley D, Skolnick P (eds), Current Protocols in Neuroscience. New York, John Wiley \& Sons, pp 8.3.1-8.3.15

File SE, Pope JH (1974): Social interaction between drugged and undrugged rats. Anim Learn Behav 2:161-164

File SE, Hyde JR (1978): Can social interaction be used to measure anxiety? Br J Pharmacol 62:19-24

File SE, Tucker JC (1984a): Lasting behavioral effects after treating rats with CGS 8216 on postnatal days 9 to 21 . Physiol Behav 32:351-356

File SE, Tucker JC (1984b): Prenatal treatment with clomipramine: effects on the behaviour of male and female adolescent rats. Psychopharmacology 82:221-224

File SE, Kenny PJ, Ouagazzal AM (1998): Bimodal modulation by nicotine of anxiety in the social interaction test: role of the dorsal hippocampus. Behav Neurosci 112:1423-1429

File SE, Fluck E, Leahy A (2001): Nicotine has calming effects on stress induced mood changes in females but enhances aggression in males. Int J Neuropsychopharmacol (in press)

Fortmann SP, Killen JD (1994): Who shall quit? Comparison of volunteer and population-based recruitment in two minimal-contact smoking cessation studies. Am J Epidemiol 140:39-51

Gardner CR, Guy AP (1984): A social interaction model of anxiety sensitive to acutely administered benzodiazepines. Drug Dev Res 4:207-216

Glassman AH, Steiner F, Walsh BT, Raizman PS, Fleiss JL, Cooper TB, Covey LS (1988): Heavy smokers, smoking cessation and clonidine. JAMA 259:2863-2866

Hatchell PC, Collins AC (1980): The influence of genotype and sex on behavioral sensitivity to nicotine in mice. Psychopharmacology 71:45-49

Health Canada (1999): National Population Health Survey High-lights. Minister of National Health and Welfare, Ottawa

Hurt RD, Sachs DP, Glover ED, Offord KP, Johnston JA, Dale LC, Khayrallah MA, Schroeder DR, Glover PN, Sullivan CR, Croghan IT, Sullivan PM (1997): A comparison of sustained-release bupropion and placebo for smoking cessation. N Engl J Med 337:1195-1202

Irvine EE, Cheeta S, File SE (1999): Time-course of changes in the social interaction test of anxiety following acute and chronic administration of nicotine. Behav Pharmacol 10:691-697

Johnston AL, File SE (1991): Sex differences in animal tests of anxiety. Physiol Behav 49:245-250

Jones BJ, Costall B, Domeney AM, Kelly ME, Naylor RJ, Oakley NR, Tyers MB (1988): The potential anxiolytic activity of GR38032F, a 5- $\mathrm{HT}_{3}$ receptor antagonist. Br J Pharmacol 93:985-993

Jorenby DE, Leischow SJ, Nides MA, Rennard SI, Johnston JA, Hughes AR, Smith SS, Muramoto ML, Daughton DM, Doan K, Fiore MC, Baker TB (1999): A controlled trial of sustained-release bupropion, a nicotine patch, or both for smoking cessation. N Engl J Med 340:685-691

Jung ME, Wallis CJ, Gatch MB, Lal H (2000): Sex differences in nicotine substitution to a pentylenetetrazol discrimi- 
native stimulus during ethanol withdrawal in rats. Psychopharmacology 149:235-240

Kabat GC, Wynder EL (1987): Determinants of quitting smoking. Am J Pub Health 77:1301-1305

Kanyt L, Stolerman IP, Chandler CJ, Saigusa T, Pogun S (1999): Influence of sex and female hormones on nicotine-induced changes in locomotor activity in rats. Pharmacol Biochem Behav 62:179-87

Kenny PJ, Cheeta S, File SE (2000): Anxiogenic effects of nicotine in the dorsal hippocampus are mediated by $5-\mathrm{HT}_{1 \mathrm{~A}}$ and not by muscarinic M1 receptors. Neuropharmacology 39:300-307

Kessler RC, Wittchen HU (1999): Anxiety, mood and substance abuse disorders: patterns and correlates of comorbidity. Eur Neuropsychopharm (Suppl 5):S142

Killen JD, Fortmann SP, Newman B, Varady A (1990): Evaluation of a treatment approach combining nicotine gum with self-guided behavioral treatments for smoking relapse prevention. J Consult Clin Psychol 58:85-92

Mortality Morbidity Weekly Report (2000a): Cigarette smoking among adults-United States. Morb Mort Week Rep 39:881-884

Mortality Morbidity Weekly Report (2000b): Youth tobacco surveillance-United States, 1998-1999. Morb Mort Week Rep CDC Surveillance Summary 49:vi-94

Morrison CF (1969): The effects of nicotine on punished behavior. Psychopharmacologia 14:221-232

Nelson DE, Giovino GA, Shopland DR, Mowery PD, Mills, SL, Eriksen MP (1995): Trends in cigarette smoking among US adolescents, 1974 through 1991. Am J Public Health 85:34-40

Niesink RJ, Van Ree JM (1982): Short-term isolation increases social interactions of male rats: a parametric analysis. Physiol Behav 29:819-825

Ouagazzal AM, Kenny PJ, File SE (1999): Stimulation of nicotinic receptors in the lateral septal nucleus increases anxiety. Eur J Neurosci 11:3957-3962

Perkins, K.A. (1999): Baseline dependency of nicotine effects: a review. Behav Pharmacol 10:597-615

Perkins KA, Donny E, Caggiula R (1999): Sex differences in nicotine effects and self administration: review of human and animal evidence. Nic Tob Res 1:301-315

Pierce JP, Gilpin E (1996): How long will today's new adolescent smoker be addicted to cigarettes? Am J Public Health 86:253-256
Pomerleau CS, Pomerleau OF, Weinstein Garcia, A (1991): Biobehavioral research on nicotine use in women. Br J Addiction 86:527-531

Prescott E, Hippe M, Schnorr P, Hein HO, Vestbo L (1998): Smoking and risk of myocardial infarction in women and men: longitudinal population study. BMJ 316:1043-1047

Primus RJ, Kellogg CK (1990): Developmental influence of gonadal function on the anxiolytic effect of diazepam on environment-related social interaction in the male rat. Behav Pharmacol 1:437-446

Royal College of Physicians (2000): Nicotine addiction in Britain: A report of the tobacco advisory group. Suffolk, The Lavenham Press Ltd

Schecter MD, Rosecrans JA (1971): CNS effects of nicotine as the discriminative stimulus for the rat in a T-maze. Life Sci 10:821-832

Seguire M, Chalmers KI (2000): Late adolescent female smoking. J Adv Nurs 6:1422-1429

Spear LP (2000): The adolescent brain and age-related behavioral manifestations. Neurosci Biobehav Rev 24:417-463

Spear LP, Brake SC (1983): Periadolescence: age-dependent behavior and psychopharmacological responsivity in rats. Dev Psychobiol 16:83-109

Stanton WR (1995): DSM-III-R tobacco dependence and quitting during late adolescence. Addict Behav 20:595-603

Stanton WR, McClelland M, Elwood C, Ferry D, Silva PA (1996): Prevalence, reliability and bias of adolescents' reports of smoking and quitting. Addiction 91:1705-1714

Trauth JA, McCook EC, Seidler FJ, Slotkin TA (2000a): Modeling adolescent nicotine exposure: effects on cholinergic systems in rat brain regions. Brain Res 873:18-25

Trauth JA, Seidler FJ, Slotkin TA (2000b): Persistent and delayed behavioral changes after nicotine treatment in adolescent rats. Brain Res 880:167-172

Vale AL, Green S (1996): Effects of chlordiazepoxide, nicotine and $d$-amphetamine in the rat potentiated startle model of anxiety. Behav Pharmacol 7:138-143

Varlinskaya EI, Spear LP, Spear NE (1999): Social behavior and social motivation in adolescent rats: role of housing conditions and partner's activity. Physiol Behav 67:475482

Zang EA, Wynder EL (1996): Differences in lung cancer risk between men and women: examination of the evidence. J Natl Cancer Inst 88:183-192 